\title{
Rare Case of Large Antesternal Goitre
}

\author{
Kunal Malhotra ${ }^{1}$, Subhash Sharma², Ashok Kumar Kaundal ${ }^{3}$, Anil Malhotra ${ }^{4}$
}

\begin{abstract}
${ }^{1}$ Department of Surgery, Indira Gandhi Medical College and Hospital, Shimla, Himachal Pradesh, India. 2Department of Surgery, Indira Gandhi Medical College and Hospital, Shimla, Himachal Pradesh, India. ${ }^{3}$ Department of Surgery, Indira Gandhi Medical College and Hospital, Shimla, Himachal Pradesh, India. ${ }^{4}$ Department of Surgery, Indira Gandhi Medical College and Hospital, Shimla, Himachal Pradesh, India.
\end{abstract}

\section{PRESENTATION OF CASE}

A 55 years male presented with a large, painless, gradually increasing swelling in the neck and antesternal area for the last 35 years. The swelling started growing in front of the neck and later on occupied the areas in front of the chest. Patient was having constant dragging sensation due to this swelling and this swelling had to be supported during eating and drinking \& it was interfering in his normal daily activities. When the growth developed small ulcer on its lower part, he reported to I.G. Medical College Hospital. The patient had no concomitant morbidity, no past history of any surgical or medical disease or treatment. There was no relevant family medical history.

\section{CLINICAL DIAGNOSIS}

The swelling was situated in the lower part in the middle of the neck and was hanging over the upper part of the chest wall covering the manubrium sterni (fig.1). The swelling was oval in shape; about $35 \mathrm{~cm} \mathrm{X} 27 \mathrm{~cm}$ in size in its largest dimensions, moved up on swallowing and it was pendulous over the sternum. The skin covering the swelling was smooth, shiny and veins below were visible. The surface of the swelling was nodular and the swelling had a variable firm to soft consistency. It had a well-defined pedicle from where it rested on crest. It could also be freely moved about sideways. There was small $2.5 \mathrm{cms} \times 1.75 \mathrm{cms}$ trophic ulcer on lower border the swelling. The swelling was non- pulsatile and had no bruit on auscultation. There were no clinical features of disturbed thyroid function and patient was clinically euthyroid. The possibility of antesternal large goitre was kept.

\section{DIFFERENTIAL DIAGNOSIS}

Benign swellings-

Branchial cyst (congenital), lipoma, fibrolipoma, neurofibroma or extra cranial schwannomas with mucoid degeneration, haemorrhage and necrosis, haemorrhage in multinodular goitre and hydatid cyst.

Inflammatory swellings-

tubercular lymphadenitis leading to cold abscess, cellulites and pyogenic abscesses.

Malignant swellings-

Fibro- sarcoma, malignant change in multinodular goitre, cystic metastatic lymph nodes from papillary carcinoma of thyroid, metastatic and necrosed lymph nodes.
Corresponding Author: Dr. Kunal Malhotra, Kushal Kunj, Near JCB Public School, Sector-3, New Shimla-171009,

Himachal Pradesh, India.

E-mail: anilkushalmalhotra@gmail.com

DOI: $10.14260 / j e m d s / 2020 / 284$

Financial or Other Competing Interests: None.

How to Cite This Article:

Malhotra K, Sharma S, Kaundal AK, et al. Rare case of large antesternal goitre. J. Evolution Med. Dent. Sci. 2020;9(15):13101312, DOI: 10.14260/jemds/2020/284

Submission 27-01-2020,

Peer Review 22-03-2020,

Acceptance 28-03-2020,

Published 13-04-2020.

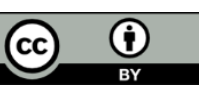




\section{PATHOLOGICAL DISCUSSION}

Goitres (from the Latin guttur, throat), means an enlargement of the thyroid, has been a recognized as a medical condition since 2700 B.C., even though the thyroid gland itself was not documented until the Renaissance period. In 1619, Hieronymus Fabricius ab Aquapendente recognized that goitres arise from the thyroid gland. The actual term thyroid gland (Greek thyreoeides, shield-shaped) is, however, attributed to Thomas Wharton in Adenographia (1656).[1] Diffusely enlarged thyroid glands can cause compressive symptoms involving the trachea, esophagus, and recurrent laryngeal nerve. These symptoms are usually associated with malignant goitres, and benign nodular goitres do not normally cause obstructive symptoms. A multi-nodular goitre is simply a thyroid gland that is usually enlarged and contains multiple thyroid nodules. The nodules can be very small, often only a few millimeters in size, or can be larger, perhaps several $\mathrm{cm}$ each. ${ }^{[2]}$ The normal adult thyroid gland weighs $10-25$ g. ${ }^{[3]}$ The term endemic goitre refers to the occurrence of goitre in a significant proportion of individuals in a particular geographic region.[1]

Worldwide, the most common cause of goitre is iodine deficiency. In fact, it has been estimated that goitres affect as many as 200 million of the 800 million people who have a diet deficient in iodine.[3]

Currently, iodine deficiency disorder is associated with the presence of endemic goitre in India, China, Central Asia, and Central Africa. Endemic goitre is thought to be caused by TSH stimulation resulting from inadequate thyroid hormone and other paracrine growth factor synthesis. Thus, the thyroid gland enlarges in an attempt to maintain a euthyroid state.[1] The general investing layer of the deep fascia of neck, which is strong and thick anteriorly, along with sternohyoid and sternothyroid muscles, prevents forward enlargement of thyroid, by the attachment of these muscles to the manubrium sterni and downward extension of the thyroid is normally directed into the superior mediastinum. ${ }^{[4]}$ In this case, the anterior support was anatomically weak and the goitre showed unchecked forward expansion, by its protrusion through the weak anterior layer and it became antesternal instead of passing down into the chest. The strap muscles could have been weak either congenitally or from their giving way as a result of sudden enlargement of the thyroid due to haemorrhage within the goitre. Such goitre should not produce pressure effects on the trachea, esophagus or recurrent laryngeal nerve.[5] However in present case the trachea was pulled anteriorly, making an anteroposterior curve, because of dragging pull of the hanging goitre, acute respiratory obstruction due to forward angulations and kinking of the trachea might have resulted. Antesternal goitre is an unusual presentation an enlarged thyroid, usually resulting from multi-nodular goiter.[6]

Diffusely enlarged thyroid glands can cause compressive symptoms involving the trachea, esophagus, and recurrent laryngeal nerve. Some of these compressive symptoms can include dyspnea, strider, orthopnea, dysphasia, or hoarseness. This is particularly concerning when there is a substernal component to these lesions, because any sudden growth in gland size would occur and could seriously compromise respiration. ${ }^{[7]}$ However, these specific symptoms can also occur in malignant goiters. ${ }^{[2]}$ The risk of malignancy in dominant nodules within multi-nodular goitres is approximately $10 \%{ }^{[8]}$ Such malignancies can be extremely slow growing and may be present for many years before being discovered. ${ }^{[9]}$
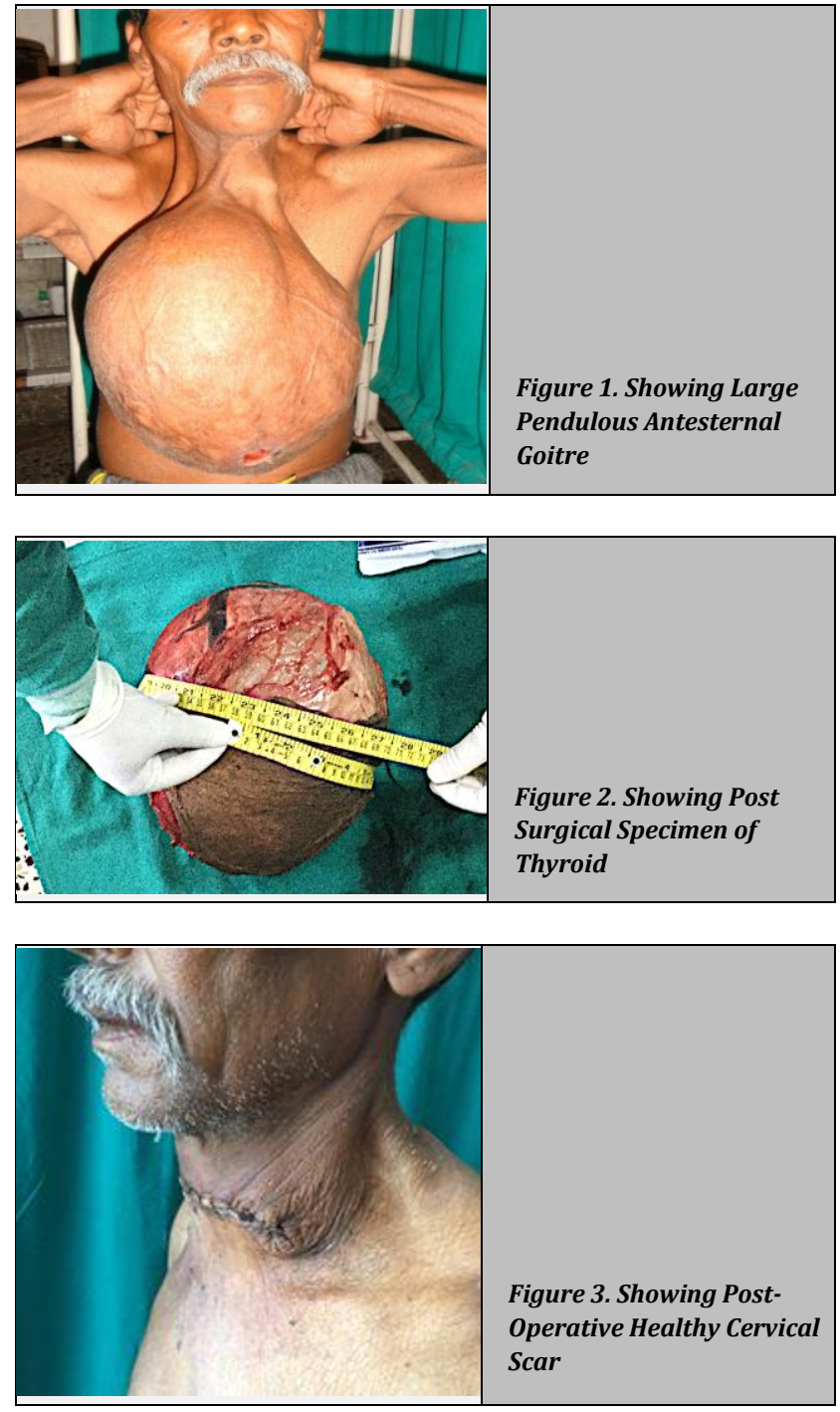

DISCUSSION OF MANAGEMENT

Patient was admitted in the hospital and investigated. All hematological and biochemical investigations were normal. A thyroid hormone profile confirmed the euthyroid status of the patient during routine preoperative tests. Urine examination and ECG showed no appreciable disease. Movements of vocal cords were normal on laryngoscopy. CT scan neck and chest showed trachea was pulled forward, anteriorly and to the left side, with goitre arising from both lobes of thyroid and isthmus. The carotid vessels were not involved by the goitre and goitre was anterior to the chest wall without any retrosternal extension. Both the lungs were normal. Ultrasound guided fine needle aspiration cytology (FNAC) from prominent nodules showed it to be multinodular goitre. Therefore, the decision to operate was made based on the patient's complaints and the possibility of a hidden malignancy. This condition requires an unconventional approach. ${ }^{6}$ 
During surgery, contrary to our expectations, we were able to smoothly intubate the patient. An elliptical incision was made around the pedicle of the goitre for a better skin closure after removal. The strap muscles had thinned out and had to be cut for proper exposure. All the vessels were tortuous, thinwalled and curving forward and upward. Feeding and draining vessels were megalised and engorged. The superior thyroid pedicle was most affected. Although feeding vessels were not at their anatomical landmarks but were ligated safely. The main vessels, being tortuous and thin walled, required careful handling during operation.

We proceeded with formal total thyroidectomy, starting with the right lobe. Although we could not identify the recurrent laryngeal nerves, but we were able to identify and preserve parathyroid glands. After completion of the thyroidectomy, no tracheomalacia was observed. Closure of the wound was quite difficult because of the thinned-out strap muscles, nearly atrophied platysma muscle and the redundant skin. The patient was kept under our supervision in the hospital for 5 days, with no postoperative complications and discharged (fig. 3).

Surgical excision can immediately resolve local symptoms and is often recommended. Although goitres have been reported to decrease by up to $40 \%$ after radio-active iodine treatment, such therapy may not sufficiently diminish the size of the large gland and could even cause temporary gland enlargement due to subsequent edema. These enlarged thyroid glands can also be of cosmetic concern for some patients, who opt for surgical excision of the lobe or gland for this reason ${ }^{9}$. Although the surgical technique used was routine; such huge goitres must be taken seriously and should be operated by experienced surgeons with full preoperative work up and precautionary measures.

\section{FINAL DIAGNOSIS}

Multi-nodular goitre with multiple cysts and areas of haemorrhage and necrosis.

The resulting thyroid specimen was $35 \times 27 \mathrm{~cm}$ in its largest dimensions and had circumference of $57 \mathrm{cms} \&$ weighed 4.0
Kg (fig. 2). On cut section, irregular nodules containing variable amount of gelatinous, brown colloids were present along with areas of haemorrhage, fibrosis, calcification and cystic changes. The microscopic appearance included colloidrich follicles lining with flattened, inactive epithelium and areas of follicular hyperplasia, accompanied by the degenerative changes.

\section{REFERENCES}

[1] Clark OH, Lal G. Thyroid, parathyroid and adrenal. In: Brunicardi FC, Anderson DK, Billiar TR, et al. eds. Schwartz's Principles of surgery. $8^{\text {th }}$ edn. The McGrawHill Companies, 2007;2:37.

[2] Wilson JD, Foster DW. The Thyroid gland. In: Williams Textbook of Endocrinology. $8^{\text {th }}$ edn. Harcourt Brace \& Company, 1992: p. 463-5.

[3] Becker KL, Bilezikian JP, Bremner WJ. Nontoxic goiter. In: Principles and practice of endocrinology and metabolism. $2^{\text {nd }}$ edn. Lippincott Williams \& Wilkins 1995: p. 338-45.

[4] Lisser H, Escamilla RF. Atlas of clinical endocrinology. $2^{\text {nd }}$ edn. St. Louis: C.V Mosby Company, 1962: p. 135.

[5] De Quervain F. Goitre and thyroid disease. New York: William Wood \& Company, 1924: p. 247.

[6] Mullick RN, Merwaha DC, Gupta RL, et al. Antesternal pendulant goitre: a case report. Br J Surg 1974;61 (5):371-2.

[7] Clark OH, Caron NR. Endocrine surgery - fine needle aspiration biopsy of the thyroid: thyroid lobectomy and subtotal and total 12 thyroidectomy. In: Fischer JE, edr. Mastery of surgery. $5^{\text {th }}$ edn. Lippincott Williams \& Wilkins 2007;1:34.

[8] Smith D, Leese G. Disorders of the thyroid glands. In: Cuschieri A, Grace PA, Darzi A, eds. Clinical surgery. $2^{\text {nd }}$ edn. Blackwell Publication 2003: p. 444.

[9] Harrison BJ, Maddox PR, Smith DM. Disorders of the thyroid gland. In: Cuschieri A, Steel RJC, Mossa AR, eds. Essential surgical practice. $4^{\text {th }}$ edn. London: Arnold Publishers 2002: p. 102. 